А.Г.Чучалин ${ }^{1}$, А.С.Белевский ${ }^{1}$, Б.А. Черняк ${ }^{2}$, Я.Г.Алексеева ${ }^{3}$, И.Н.Трофименко ${ }^{2}$, А.С.Зайцева ${ }^{3}$

Качество жизни больных хронической обструктивной болезнью легких в России: результаты многоцентрового популяционного исследования «ИКАР-ХОБЛ"

${ }^{1}$ НИИ пульмонологии МЗ и СР РФ; ${ }^{2}$ Иркутский институт усовершенствования врачей; ${ }^{3}$ ГУЗ Отделенческая клиническая больница ст. Волгоград-1

Chuchalin A.G., Belevsky A.S., Chernyak B.A., Alexeeva Ya.G., Trofimenko I.N., Zaitseva A.S.

\title{
Quality of life in chronic obstructive pulmonary disease patients in Russia: results of "IKAR-COPD" multi-center population-based study
}

\section{Summary}

The objective of the "IKAR-COPD" study was to evaluate quality of life in COPD patients with different treatment regimens. This multi-center population-based study was performed in 10 regions of Russia, 702 COPD patients aged 40 to 85 yrs were included in this study: $18.5 \%$ with COPD stage I, $20.7 \%$ with COPD stage II, $40.9 \%$ with COPD stage III and $19.9 \%$ with COPD stage IV (according to the GOLD 2003 criteria).

The official Russian versions of the MOS SF-36 questionnaire and the St. George's Respiratory Questionnaire (SGRQ) were used as generic and disease-specific health-related measures of quality of life.

COPD significantly impaired the patients' quality of life, mostly their physical activity. The quality of life depended on severity of COPD, a patient's age, duration of the disease and smoking history.

\section{Резюме}

Целью исследования «ИКАР-ХОБЛ» было изучение влияния хронической обструктивной болезни легких (ХОБЛ) и тактики ее лечения на качество жизни (КЖ) больных.

Многоцентровое популяционное исследование проведено в 10 регионах РФ. В него были включено 702 пациента с ХОБЛ в возрасте от 40 до 85 лет: 18,5\% пациентов - с I стадией, 20,7 \% - со II стадией, 40,9\% - с III стадией и $19,9 \%$ - с IV стадией ХОБЛ (по критериям $G O L D, 2003$ ).

Исследование КЖ проводилось с использованием общего «Краткого вопросника оценки статуса здоровья» (официального русскоязычного аналога вопросника $M O S S F-36)$, и русскоязычной версии «Респираторного вопросника госпиталя Святого Георгия»-St. George's Respiratory Questionnaire (SGRQ).

Выявлено, что ХОБЛ оказывает выраженное негативное воздействие на КЖ пациентов, в первую очередь на их физический статус. Выраженность отклонений определяется степенью тяжести ХОБЛ, возрастом пациентов, длительностью заболевания, индексом курения.

Хроническая обструктивная болезнь легких (ХОБЛ) является одной из важнейших проблем здравоохранения [1]. Результаты эпидемиологических исследований свидетельствуют о высокой распространенности данной патологии [2, 3]. Так, в США в 1995 г. насчитывалось свыше 12 млн больных ХОБЛ, за последние 10 лет их число выросло на 41,5\% [4]. Несмотря на успехи, достигнутые в течение последнего десятилетия в лечении пациентов с обструктивными заболеваниями легких, возможности терапии ХОБЛ остаются достаточно ограниченными. Это объясняется тем, что основной особенностью ХОБЛ является неуклонное прогрессирование бронхиальной обструкции, лишь частично обратимой под воздействием современных методов лечения, развитие и прогрессирование хронической дыхательной недостаточности и хронического легочного сердца [5], а также системное влияние болезни на организм [6]. При этом такие важные показатели здоровья, как смертность, число госпитали-

http://www.pulmonology.ru заций и ОФВ оценки эффективности проводимой терапии при обструктивных болезнях легких, к сожалению, полностью не отражают самочувствие пациента с ХОБЛ и уровень его здоровья. Полагаясь исключительно на них, в некоторых случаях можно прийти к выводу об отсутствии влияния лечения на смертность при ХОБЛ или к заключению о том, что ОФВ 1 может значительно улучшить жизнеспособность пациента и его функциональную активность [7]. В связи с этим трудно переоценить важность изучения качества жизни (КЖ) у данной категории пациентов, а повышение КЖ, также как и улучшение симптоматики, необходимо рассматривать в качестве важной цели проводимой терапии ХОБЛ. При этом результаты субъективной оценки здоровья самим пациентом часто наиболее достоверны и важны, поскольку способны отразить различные аспекты его здоровья, ожидания, а также отношение к лечению и степень удовлетворенности им [7]. Именно этим 
объясняется значительный рост числа исследований, использующих КЖ как один из критериев эффективности различных методов лечения при бронхиальной астме (АБ) и ХОБЛ.

Реализация в России в 2001-2002 гг. многоцентрового проекта «ИКАР» способствовало выявлению общих закономерностей влияния БА и современных методов ее лечения на КЖ пациентов с этой патологией. Подобные исследования при ХОБЛ до настоящего времени в России не проводились.

Целью исследования «ИКАР-ХОБЛ» являлось изучение влияния ХОБЛ и тактики ее лечения на КЖ больных.

\section{Субъекты исследования и методы}

Исследование было выполнено в дизайне многоцентрового популяционного исследования, в котором приняли участие 13 центров в 10 регионах РФ: Барнаул (координатор исследования - Мартыненко Т.И.), Волгоград (Сосонная Н.А.), Екатеринбург (Лещенко И.В.), Иркутск (Черняк Б.А.), Казань (Фассахов Р.С.), Москва (Белевский А.С., Овчаренко С.И., Шмелев Е.И., Шмелева Н.М.), Самара (Жестков А.В.), Санкт-Петербург (Трофимов В.И.), Смоленск (Пунин А.А.), Ярославль (Палютин ШІ.Х.).

В исследование включались пациенты с ХОБЛ в возрасте старше 40 лет, находящиеся на амбулаторном лечении и имеющие индекс курения $\geq 10$ пачко-лет (в т. ч. для «бывших курильщиков»).

Верификация диагноза ХОБЛ и оценка степени тяжести проводилась в соответствии с критериями $G O L D$ [8]. Наличие ХОБЛ должно было быть подтверждено анамнестически и инструментальНо (ОФВ 1 ФЖЕЛ $<70 \%$, прирост ОФВ $1 \leq 12 \%$ и $\leq 200$ мл при проведении пробы с $\beta$-агонистом). В исследование не включались пациенты, имевшие острые заболевания и обострение / декомпенсацию хронических заболеваний на момент анкетирования (в т. ч. ХОБЛ), а также лица, находившиеся на стационарном лечении или перенесшие оперативное вмешательство в течение последних 4 нед. У респондентов могли быть сопутствующие хронические заболевания вне обострения, если они не требовали увеличения объема проводимой терапии на момент включения в исследование.

K I стадии (легкая ХОБЛ) были отнесены пациенты с ОФВ 1 ФЖЕЛ $<70 \%$, ОФВ $_{1} \geq 80 \%$ от должных величин, с наличием или без респираторных симптомов (хронический кашель и продукция мокроты). Ко II стадии (среднетяжелая ХОБЛ) - лица с ОФВ $/$ ФЖЕЛ $<70 \%$ и ОФВ от 50 до $79 \%$ от должных величин, к III стадии (тяжелая ХОБЛ) - пациенты с ОФВ $/$ ФЖЕЛ < $70 \%$ и ОФВ $30-49 \%$ от должных величин. K IV стадии (крайне тяжелая ХОБЛ) были отнесены лица с ОФВ $/$ ФЖЕЛ $<70 \%$ и ОФВ $<30 \%$ от должных величин или ОФВ $<50 \%$ от должных величин при наличии признаков хронической дыхательной недостаточности или хронического легочного сердца.

Выраженность респираторных симптомов (кашель, продукция мокроты, одышка) оценивалась с использованием формализованных балльных шкал, где 0 - отсутствие признака, а 3 балла (при оценке выраженности одышки - 5 баллов) максимальная выраженность симптома.

Исследование КЖ проводилось методом самоанкетирования с использованием общего «Краткого вопросника оценки статуса здоровья» (официального русскоязычного аналога вопросника MOS SF-36 [9]), и русскоязычной версии «Респираторного вопросника госпиталя Святого Георгия» - St. George's Respiratory Questionnaire (SGRQ) [10].

На основании результатов анкетирования по вопроснику $M O S S F-36$ проводился расчет 5 показателей, характеризующих физический статус респондента (физическая активность - ФА, роль физических проблем в ограничении жизнедеятельности - РФ, боль - Б, общее здоровье - О3, жизнеспособность - ЖС), и 5 параметров, отражающих его психо-социальный статус (роль эмоциональных проблем в ограничении жизнедеятельности - РЭ, социальная активность - СА, психическое здоровье - ПЗ, общее здоровье О3 и жизнеспособность - ЖС). Два последних показателя определяются как физическим, так и психическим статусом человека. Параметры общего КЖ оценивались по 100-балльной шкале. При этом такие показатели КЖ как ФА, О3, ЖС, СА и ПЗ оценивались как «прямые», т. е., чем выше оценка, тем лучше КЖ пациента, а РФ, Б, РЭ оценивались как «обратные» критерии, т. е., чем выше значение данного показателя, тем менее выражено его влияние на КЖ человека.

Для исследования специфического КЖ, оцениваемого с помощью вопросника $S G R Q$, рассчитывались 3 основных показателя: симптомы, позволяющие оценить степень выраженности респираторных симптомов; активность, характеризуюшую степень ограничения физической активности в результате ХОБЛ; воздействие, которым оценивается влияние психологических проблем, обусловленных заболеванием, а также суммарный балл, характеризующий общее воздействие болезни на статус здоровья пациента. Последний показатель рассчитывался как алгебраическая сумма баллов по 3 основным шкалам вопросника $S G R Q$. Более высокая оценка соответствовала более тяжелому течению заболевания. Изменение показателей на 4 балла и более считались клинически значимыми.

Статистическая обработка проводилась с использованием статистического пакета SPSS for 


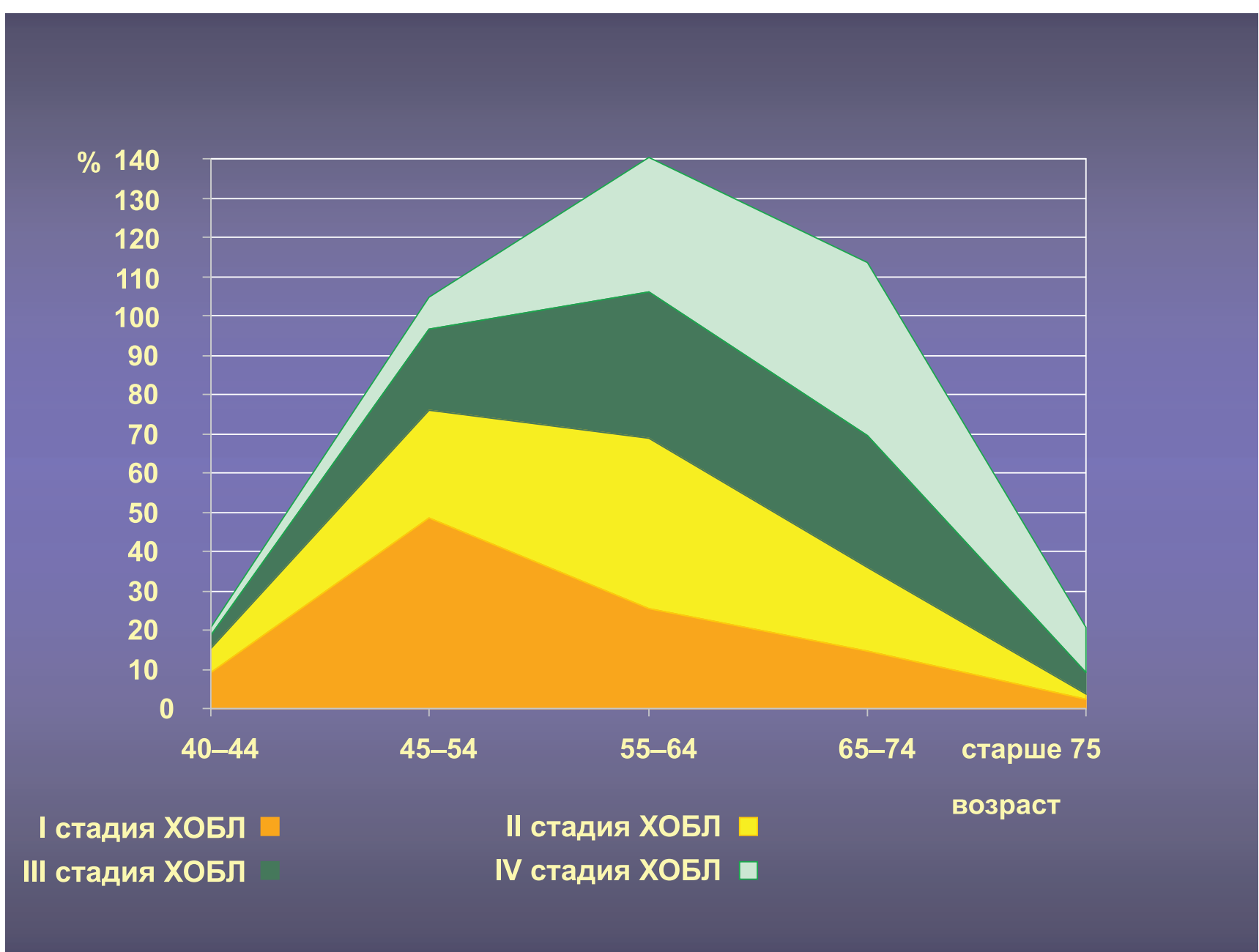

Рис. 1. Соотношение пациентов по степени тяжести ХОБЛ в зависимости от возраста (\%)

Windows v. 11.5 (SPSS Inc., 1989-2002). Значимые изменения в показателях КЖ оценивались с использованием однофакторного дисперсионного анализа. Статистически значимыми различия считались при $P<0,05$.

\section{Результаты исследования и обсуждение}

В соответствии с критериями отбора в исследование были включены 702 пациента с ХОБЛ в возрасте от 40 до 85 лет (Северо-Западный федеральный округ - 56 больных, Центральный округ (кроме Москвы) - 100 больных, Москва - 196 больных, Южный округ -89 больных, Приволжский округ - 100 больных, Сибирский округ 111 больных, Уральский округ - 50 больных), из них 586 мужчин и 116 женщин. Средняя длительность ХОБЛ в исследуемой популяции составила $9,9 \pm 0,3$ лет.

У 130 пациентов $(18,5 \%)$ тяжесть ХОБЛ соответствовала I стадии (по критериям GOLD, 2003), у 145 пациентов (20,7 \%) - II стадии, у 287 $(40,9 \%)$ - III стадии и у $140(19,9 \%)-$ IV стадии ХОБЛ. При этом с возрастом тяжесть заболевания прогрессировала (рис. 1). Так, в возрас- те 40-54 лет большинство пациентов ( 75 / 206, $36,4 \%)$ имеют легкую ХОБЛ, тогда как после 65 лет у подавляющего числа пациентов (190 / 245, $77,5 \%$ ) степень тяжести заболевания соответствует тяжелой и крайне тяжелой ХОБЛ. Независимо от возраста и степени тяжести заболевания, среди пациентов преобладали лица мужского пола $(83,5 \%)$. Однако при прогрессировании заболевания данная тенденция усиливалась, и если при легкой и среднетяжелой ХОБЛ доля мужчин составила 78,5\% (102/130) и 77,9\% (113/145) соответственно, то при тяжелой и крайне тяжелой степени - 85,7\% (246/287) и 89,3\% (125/140) соответственно.

Уровень образования больных с ХОБЛ существенно не отличался от среднепопуляционных значений. Так, среди пациентов с ХОБЛ, как и в популяции в целом, преобладали лица со средним специальным / неполным высшим образованием (42,2\% и $38,3 \%$ соответственно). Число респондентов с высшим и средним образованием в обеих группах также было сопоставимо и составило при ХОБЛ $29,2 \%$ и $28,6 \%$ соответственно, а в популяции в целом - 33,1\% и 28,6\% соответственно. При этом среди пациентов с легкой и среднетяжелой ХОБЛ образовательный уровень был выше, 
чем при тяжелом и крайне тяжелом течение заболевания: высшее образование имели 33,1 \% опрошенных - с легким, 35,2\% пациентов - со среднетяжелым ХОБЛ, 28,2 \% - с тяжелым и 21,4\%с крайне тяжелым течением заболевания.

Выявлены определенные различия в профессиональной занятости респондентов. Соотношение работающих и неработающих респондентов составило среди больных ХОБЛ $46,0 \%$ и $54,0 \%$, а в популяции $-68,8 \%$ и $31,2 \%$ соответственно. При этом уровень незанятости возрастал при прогрессировании заболевания. Так, если при легкой ХОБЛ не работало всего $28,5 \%$ опрошенных, то среди пациентов с крайне тяжелой ХОБЛ этот уровень достиг $89,3 \%$.

Среди пациентов с ХОБЛ, включенных в исследование, преобладали лица, состоящие в браке $(81,2 \%)$. Кроме того, процент одиноко живущих практически не зависел от степени тяжести ХОБЛ (при легкой - 21,5\%, при среднетяжелой $15,2 \%$, при тяжелой $-18,1 \%$, и при крайне тяжелой ХОБЛ $-1,4 \%)$.

Полученные данные об уровне доходов продемонстрировали, что показатель при ХОБЛ сопоставим со средне популяционными значениями: практически в половине случаев (51\%) средний доход на 1 члена семьи в семьях больных ХОБЛ составил $1000-3000$ р., и лишь у $3,7 \%$ и $0,7 \%$ опрошенных средний доход превысил 5000 р. и 10000 p. соответственно. Более показательные различия в отношении уровня доходов выявлены в зависимости от тяжести ХОБЛ, что свидетельствует об инвалидизирующем влиянии ХОБЛ, снижении трудоспособности и ухудшении материального положения пациентов (табл. 1).

Распределение затрат на лечение ХОБЛ в зависимости от тяжести заболевания имеет обратную тенденцию: более половины больных с легкой ХОБЛ тратят на лечение меньше 250 р. в месяц $(60,8 \%)$, тогда как $39,4 \%$ пациентов с тяжелой и $35,0 \%$ с крайне тяжелой степенью заболевания тратят не менее 250 р., а 20,6\% и 22,9\% соответственно - более 500 р. в месяц.

Диагностика ХОБЛ основывается на анамнестических данных о воздействии факторов риска и инструментальном подтверждении обструкции дыхательных путей, которая не полностью обратима под воздействием бронхолитиков.

Одним из наиболее изученных факторов риска ХОБЛ является курение табака [11]. Большая часть респондентов $(71,2 \%)$ на момент проведения исследования продолжали курить. Индекс курения среди них, как в целом в группе, так и по степеням тяжести ХОБЛ, был несколько выше, чем в группе экс-курильщиков (33,9 $\pm 0,8$ и $-26,6 \pm$ 1,1 пачко-лет соответственно). При этом в обеих группах выявлена зависимость тяжести ХОБЛ от интенсивности и длительности стажа курения (табл. 2).
Таблица 1

Уровень дохода на 1 илена семьи в зависимости от тяжести ХОБЛ

\begin{tabular}{|l|c|c|c|c|}
\hline \multicolumn{1}{|c|}{ Тяжесть ХОБЛ } & І стадия & II стадия & ІІІ стадия & IV стадия \\
\hline Число, $N$ & 130 & 145 & 287 & 140 \\
& & & & \\
\hline$<1000$ p. & $4,6 \%$ & $5,5 \%$ & $1,4 \%$ & $1,4 \%$ \\
& $6 / 130$ & $8 / 145$ & $4 / 287$ & $2 / 140$ \\
\hline $1000-3000$ p. & $43,8 \%$ & $45,5 \%$ & $49,8 \%$ & $65,7 \%$ \\
& $57 / 130$ & $66 / 145$ & $143 / 287$ & $92 / 140$ \\
\hline $3000-6000$ p. & $30,0 \%$ & $25,5 \%$ & $21,6 \%$ & $13,6 \%$ \\
& $39 / 130$ & $37 / 145$ & $62 / 287$ & $19 / 140$ \\
\hline $6000-10000$ p. & $1,5 \%$ & $6,2 \%$ & $4,9 \%$ & $0,7 \%$ \\
& $2 / 130$ & $9 / 145$ & $14 / 287$ & $1 / 140$ \\
\hline$>10000$ p. & $1,5 \%$ & $1,4 \%$ & - & $0,7 \%$ \\
& $2 / 130$ & $2 / 145$ & & $1 / 140$ \\
\hline
\end{tabular}

Таблица 2

Влияние индекса курения на тяжесть ХОБЛ

\begin{tabular}{|l|c|c|c|}
\hline Тяжесть ХОБл & Курильщики & Экс-курильщики & $p$ \\
\hline I стадия & $27,3 \pm 1,3$ & $20,8 \pm 2,1$ & $<0,01$ \\
\hline II стадия & $35,2 \pm 1,8$ & $22,1 \pm 1,8$ & $<0,001$ \\
\hline III стадия & $34,8 \pm 1,2$ & $28,8 \pm 1,9$ & $<0,01$ \\
\hline IV стадия & $37,6 \pm 1,6$ & $31,4 \pm 2,0$ & $<0,05$ \\
\hline
\end{tabular}

Таблица 3.

Выражснность симптомов в зависимости от тяжести ХОБЛ

\begin{tabular}{|l|c|c|c|c|}
\hline $\begin{array}{c}\text { Тяжесть } \\
\text { ХОБл }\end{array}$ & Кашель & Мокрота & Одышка & $p$ \\
\hline I стадия & $1,28 \pm 0,06$ & $0,85 \pm 0,04$ & $1,44 \pm 0,08$ & $<0,001$ \\
\hline II стадия & $1,87 \pm 0,07$ & $1,12 \pm 0,03$ & $2,22 \pm 0,07$ & $<0,001$ \\
\hline III стадия & $2,30 \pm 0,05$ & $1,29 \pm 0,03$ & $3,07 \pm 0,05$ & $<0,001$ \\
\hline IV стадия & $2,69 \pm 0,08$ & $1,46 \pm 0,05$ & $3,89 \pm 0,07$ & $<0,001$ \\
\hline
\end{tabular}

Примечание: $p$ - стандартная ошибка среднего, по сравнению со стадией ХОБЛ.

Результаты исследования подтвердили неуклонное прогрессирование ХОБЛ с течением времени. Выявлена прямая корреляционная зависимость между тяжестью ХОБЛ и длительностью заболевания $(r=0,42, p<0,01)$. При этом средняя продолжительность заболевания у пациентов с легкой, среднетяжелой, тяжелой и крайне тяжелой ХОБЛ составила 5,5 \pm 0,5, 8,7 $\pm 0,5,10,8 \pm 0,4$ и $13,1 \pm 0,5$ лет соответственно.

Несмотря на то, что наличие респираторных симптомов (хронический кашель с выделением мокроты, одышка) является необязательным клиническим признаком ХОБЛ, выявлено их усиление по мере прогрессирования болезни (табл. 3). Более объективным показателем, принятым в качестве «золотого стандарта» для диагностики и оценки тяжести ХОБЛ, является ОФВ 1 , характеризующий степень бронхиальной обструкции. В этом аспекте клинические симптомы ХОБЛ расцениваются как зависящие от ОФВ 


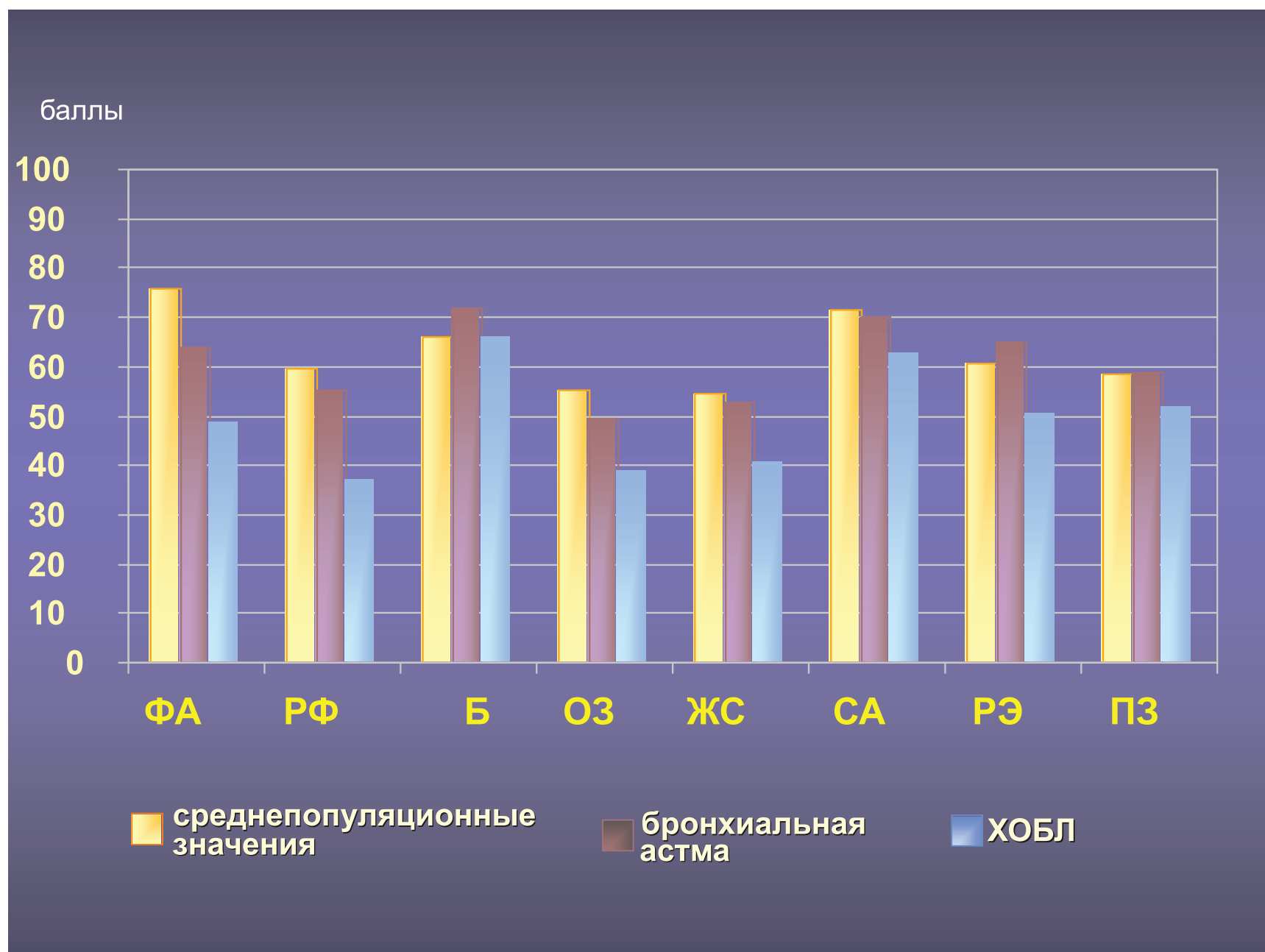

Рис. 2. Среднепопуляционные значения показателей КЖ здоровых лиц и пациентов с БА и ХОБЛ (MOS SF-36) (по результатам эпидемиологических исследований «ИКАР» и «ИКАР-ХОБЛ», 2002-2004 гг. [14])

ФА - физическая активность; РФ - роль физических проблем в ограничении жизнедеятельности; Б - боль; О3 - общее здоровье; ЖС - жизнеспособность; РЭ - роль эмоциональных проблем в ограничении жизнедеятельности; СА - социальная активность; ПЗ - психическое здоровье.

По мере прогрессирования клинических симптомов ХОБЛ (главным образом, одышки) увеличивается и потребность в бронхолитической терапии. Так, при легкой ХОБЛ 73,1\% пациентов использовали короткодействующие бронхолитики не более 1 раза в сутки, а при тяжелой и крайне тяжелой ХОБЛ более чем у половины больных $(57,2 \%$ и $77,1 \%$ соответственно) потребность в симптоматической бронхолитической терапии превышала 3 ингаляции в сутки.

Наряду с неуклонным прогрессированием ХОБЛ, для данного заболевания характерно наличие обострений, которые характеризуются усугублением симптомов болезни, ухудшают состояние здоровья больного и его КЖ [12]. Более половины обследованных больных в течение последних 3 мес. имели среднетяжелые обострения $(53,6 \%)$, а $14,4 \%$ - тяжелые обострения ХОБЛ. Частота и тяжесть обострений зависела от стадии ХОБЛ.

Адекватная терапия ХОБЛ в течение 1 мес., предшествующего исследованию, проводилась лишь у половины больных $(54,8 \%)$. Из них ко- роткодействующие ингаляционные холинолитики получали $14,7 \%$, ингаляционные $\beta$-агонисты короткого действия $-16,3 \%$, комбинированные бронхолитики - $43 \%$, длительнодействующие ингаляционные бронхолитики - $11,4 \%$, метилксантины - 38,2 \% (эуфиллин - 16,1\%, пролонгированные теофиллины - 22,1\%). 22,2\% опрошенных принимали ингаляционные ГКС или комбинированную противовоспалительную терапию (иГКС $+\beta_{2}$-агонист длительного действия). В $11,7 \%$ случаев назначались системные ГКС, длительное применение которых при ХОБЛ нерекомендовано, учитывая отсутствие доказательств долгосрочной эффективности и большой спектр побочных эффектов такого лечения [13]. При этом, несмотря на наличие клинических симптомов, выраженность и прогрессирование обструкции дыхательных путей, 19,2\% пациентов не получали никакого лечения, а 38,9 \% получали препараты с недоказанной эффективностью при лечении ХОБЛ.

Изучение КЖ больных ХОБЛ выявило значительное снижение его показателей, по сравнению 
Влияние длительности БА и ХОБЛ на качество жизни пациентов (баллы)

\begin{tabular}{|l|l|l|l|l|l|l|l|l|l|}
\hline Длительность заболевания & Заболевание & ФА & РФ & Б & 03 & ЖС & \multicolumn{1}{|c|}{ СА } & РЭ & П3 \\
\hline \multirow{2}{*}{$1-5$ лет } & БА & 68,10 & 60,64 & 75,79 & 52,70 & 55,90 & 72,83 & 68,76 & 60,67 \\
\hline & ХОБл & 62,86 & 55,10 & 71,15 & 47,02 & 49,57 & 71,27 & 66,26 & 57,21 \\
\hline \multirow{2}{*}{$5-10$ лет } & БА & 66,03 & 58,13 & 74,95 & 51,45 & 53,99 & 72,25 & 67,11 & 59,92 \\
\hline \multirow{2}{*}{$>10$ лет } & ХОБл & 47,87 & 37,78 & 66,57 & 38,59 & 41,23 & 61,94 & 51,57 & 51,12 \\
\hline
\end{tabular}

Примечание: ФА - физическая активность, РФ - роль физических проблем в ограничении жизнедеятельности, Б - боль, ОЗ - общее здоровье, ЖС - жизнеспособность, РЭ - роль эмоциональных проблем в ограничении жизнедеятельности, СА - социальная активность, ПЗ - психическое здоровье.

с популяцией в целом (исключение - показатель «боль») (рис. 2). Выраженность отклонений определялась степенью тяжести ХОБЛ, возрастом пациентов и длительностью заболевания. При этом необходимо отметить, что, несмотря на сходство клинических проявлений БА и ХОБЛ, негативное влияние последней на КЖ более выражено.

Так, у пациентов с легкой ХОБЛ выявлено незначительное снижение лишь показателя «общее здоровье» (оценка общего состояния здоровья респондентом на момент проведения исследования). Остальные показатели, характеризующие как физический, так и психический статус респондента, существенно не отличались от среднепопуляционных значений или даже превосходили таковые.

При среднетяжелой ХОБЛ отмечалось преимущественное снижение показателей, характеризующих физический статус («физическая активность, роль физических проблем в ограничении жизнедеятельности», «общее здоровье», «жизнеспособность»). Параллельно этому возросла роль психо-эмоциональных проблем. Но, несмотря на подобные изменения КЖ, больные ХОБЛ испытывали достоверно меньше болевых ощущений, чем в популяции в целом.

При тяжелой и крайне тяжелой ХОБЛ негативное влияние болезни на все компоненты КЖ прогрессивно возрастало. При этом наиболее низких значений достигли показатели, характеризующие физический статус (исключение - «боль»).

В целом, с увеличением возраста пациентов наблюдалась отчетливая тенденция к снижению всех показателей КЖ, поскольку с возрастом пациенты подвергаются более длительному воздействию неблагоприятных факторов.

Так, в возрастной группе от 40 до 44 лет отмечалось лишь незначительное снижение повседневной «физической активности», оценки «общего здоровья» и «жизнеспособности», а также недостоверное ухудшение «психического здоровья». Обращает на себя внимание парадоксальное вли- яние ХОБЛ в данном возрасте на психо-эмоциональное состояние и социальную активность.

В возрасте 45-54 лет негативное влияние ХОБЛ на показатели физического здоровья продолжало усиливаться (исключение - оценка «боли»). Однако оценка респондентами своего «общего здоровья» и «жизнеспособности» существенно не отличалась от таковой в предыдущей возрастной группе. Показатели «психического здоровья» приближались к средне популяционным значениям.

Для старшей возрастной группы (> 55 лет) характерно значимое снижение абсолютного числа показателей КЖ $(p<0,05)$, что можно объяснить увеличением случаев тяжелого течения заболевания с возрастом.

Аналогичное влияние на КЖ пациентов оказывала длительность заболевания.

Прогрессирование болезни неуклонно приводило к снижению КЖ. Характерно, что уже на ранних стадиях изменения КЖ при ХОБЛ были более выраженными, чем при БА (табл. 4). Данные различия имели тенденцию увеличиваться с течением времени. При этом негативный «опыт заболевания» быстрее влиял на показатели физической активности (ФА и РФ) и эмоциональное состояние пациентов, вызывая ограничение их функционирования, снижая оценку «общего здоровья» и «жизнеспособности».

Выраженное воздействие практически на все параметры КЖ (исключение, оценка «боли») оказывает индекс курения (число пачко-лет), которое усиливается при увеличении стажа курения $(p<0,01)$. Характерно, что при ХОБЛ, в отличие от БА, курение табака более негативно отражается на КЖ пациентов, в т. ч. у экс-курильщиков.

Хотя кашель и продукция мокроты являются важными клиническими признаками ХОБЛ, они слабо коррелируют с субъективной оценкой различных показателей КЖ, за исключением влияния выраженности кашля на показатель ФА $(r=0,49, p<0,01)$. Напротив, установлена 


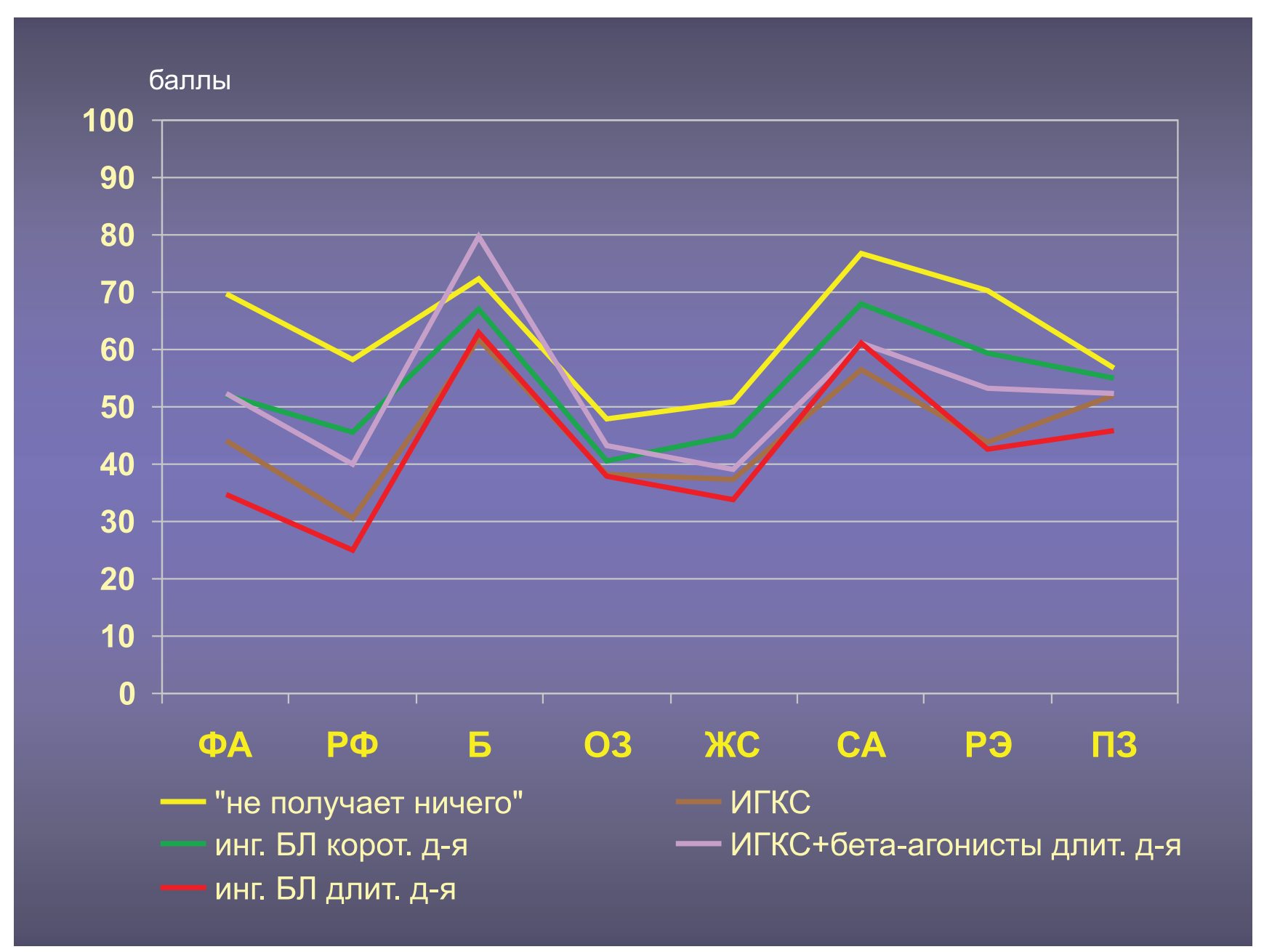

Рис. 3. Общее КЖ пациентов с ХОБЛ на фоне различных методов лечения (MOS SF-36)

ФА - физическая активность РФ - роль физических проблем в ограничении жизнедеятельности, Б - боль, ОЗ - общее здоровье, ЖС - жизнеспособность, РЭ - роль эмоциональных проблем в ограничении жизнедеятельности, СА - социальная активность, ПЗ - психическое здоровье.

четкая обратная взаимосвязь между выраженностью одышки и показателями физической активности $(r=-0,71, p<0,01)$, оценки общего здоровья $(r=-0,53, p<0,01)$ и жизнеспособности $(r=-0,51, p<0,01)$. В меньшей степени этот симптом ассоциировался с «ролевыми шкалами» (РФ и РЭ) $\quad(r=-0,48, p<0,01)$.

Закономерно, что показатели ФВД (главным образом, ОФВ $)_{1}$ также влияют на КЖ пациентов, хотя и в меньшей степени, оказывая более значимое воздействие на уровень физической активности $(r=0,66, p<0,01)$ и оценку общего здоровья $(r=0,53, p<0,01)$, скорее всего, также за счет уменьшения выраженности одышки. Однако увеличение ОФВ не способствовало существенному улучшению оценки по шкале «боль» и «психо-эмоциональное состояние» $(p<0,01)$. Аналогично воздействие на показатели КЖ и ФЖЕЛ $(p<0,01)$.

При изучении КЖ с использованием специфического инструмента $S G R Q$ было выявлено, что увеличение тяжести ХОБЛ ассоциируется с прогрессирующим ухудшением субъективной оценки пациентом статуса своего здоровья, что проявля- ется в клинически значимом (> 4 баллов) увеличении оценок по шкалам вопросника на каждой следующей стадии заболевания $(p<0,001)$. Это максимально выражено при анализе шкал «воздействие» и «суммарный балл». Причем данные изменения могут однозначно трактоваться как обусловленные ХОБЛ, независимо от наличия или отсутствия у пациентов сопутствующей патологии. При этом негативное влияние ХОБЛ на специфическое КЖ мужчин было более выражено (данные изменения касались всех параметров специфического КЖ и были клинически значимыми).

Аналогичным образом на величину показателей КЖ, полученных при использовании вопросника $S G R Q$, оказывали параметры «длительность заболевания» и «возраст пациентов» $(p<0,01)$.

Выраженность респираторных симптомов при ХОБЛ (кашель, одышка, потребность в бронхолитической терапии) и показатели ФВД (ОФВ 1 ФЖЕЛ) четко ассоциировались с низкой оценкой специфического КЖ ( $p<0,01)$, наиболее значимо - с оценкой по шкале «активность» и величиной суммарного балла. 
Таблица 5

Структура ХОБЛ в группах с различныли подходами фармакотерапии

\begin{tabular}{|c|c|c|c|c|c|}
\hline Тяжесть ХОБЛ & І стадия & II стадия & III стадия & IV стадия & Bcero \\
\hline Не получает ничего & $61 / 45,2 \%$ & 39 / 28,9 \% & $26 / 19,2 \%$ & $9 / 6,6 \%$ & 135 \\
\hline Ингаляционные бронхолитики короткого действия & $25 / 16,7 \%$ & $39 / 26 \%$ & $68 / 45,3 \%$ & $18 / 12 \%$ & 150 \\
\hline $\begin{array}{l}\text { Ингаляционные бронхолитики длительного дей- } \\
\text { ствия" }^{\text {. }}\end{array}$ & - & $6 / 20,7 \%$ & $19 / 65,5 \%$ & $4 / 13,8 \%$ & 29 \\
\hline игкс & $2 / 3,5 \%$ & $12 / 21,1 \%$ & $30 / 52,6 \%$ & $13 / 22,8 \%$ & 57 \\
\hline $\begin{array}{l}\text { фиксированная комбинация иГКС + } \beta \text {-агонист дли- } \\
\text { тельного действия" }\end{array}$ & $3 / 30 \%$ & $1 / 10 \%$ & $1 / 10 \%$ & $5 / 50 \%$ & 10 \\
\hline
\end{tabular}

Примечание: * - одновременно пациенты могли получать бронхолитики короткого действия (ингаляционные холинолитики, ингаляционные $\beta$-агонисты, комбинированные бронхолитики - беродуал) и / или мукорегуляторы.

Обращает на себя внимание влияние индекса курения на уровень специфического КЖ. В целом, оно аналогично воздействию данного внешнего фактора на общее КЖ $(p<0,01)$. Однако оценка уровня здоровья по шкалам «активность», «воздействие» и «суммарный балл» экс-курильщиками значительно ниже, чем пациентами, продолжающими активное курение, и соответствует таковой при стаже курения более 30 лет. Различия в оценке по шкале «симптомы» у пациентов, бросивших и продолжающих курить, не были клинически значимыми.

При анализе показателей КЖ на фоне различных подходов к лечению ХОБЛ выявлено парадоксальное влияние последнего на оценку как общего, так и специфического КЖ, по сравнению с альтернативой «не получает ничего» (рис. 3).

Выявленные изменения трудно объяснимы с позиции эффективности проводимой терапии. Скорее всего, они обусловлены отсутствием сопоставимости сравниваемых групп, в первую очередь по степени тяжести ХОБЛ (табл. 5). Так, среди участников исследования, у которых лечение ХОБЛ не проводилось, преобладали пациенты с легким ХОБЛ (45,2\%), у которых симптомы заболевания могут отсутствовать, а показатель ОФВ $2 \geq 80 \%$, что как правило, не требует регулярного применения препаратов. И напротив, у большей части больных, принимающих для лечения ХОБЛ ингаляционные бронхолитики, иГКС и / или фиксированную комбинацию иГКС $+\beta$-агонист длительного действия (Серетид Мультидиск, «GlaxoSmithKline», или Симбикорт Турбухалер, «AstraZeneca»), заболевание характеризовалось тяжелым и крайне тяжелым течением.

Учитывая отсутствие рандомизации данных о длительности терапии иГКС и комбинированных препаратов иГКС и $\beta_{2}$-агонистов длительного действия, дозах применяемых препаратов, выявленные изменения КЖ не могут быть проанализированы и заслуживают дальнейшего изучения.
В целом же полученные результаты исследования КЖ подтверждают меньшую эффективность известных методов фармакотерапии ХОБЛ, по сравнению с БА, т. к., по данным литературы, ни один препарат, применяемый для лечения ХОБЛ, не позволяет предупредить снижение функции легких, а также присоединение и нарастание признаков хронической дыхательной недостаточности на более поздних стадиях заболевания [11, 15-16].

\section{Выводы}

1. ХОБЛ оказывает негативное воздействие на КЖ пациентов, в первую очередь на их физический статус.

2. Степень негативного влияния ХОБЛ на КЖ пациентов определяется степенью тяжести заболевания, его длительностью и возрастом пациента.

3. Выраженность клинических симптомов при ХОБЛ (исключение - одышка) слабо коррелирует с субъективной оценкой статуса здоровья пациентом. Поэтому исследование КЖ является важным показателем контроля над течением ХОБЛ, который позволяет дополнить данные мониторинга ФВД, отражающие преимущественно функциональный статус пациента.

4. Эффективность противовоспалительной терапии при ХОБЛ, в т. ч. с позиции ее влияния на КЖ пациентов, требует дальнейшего изучения.

\section{Литература}

1. World Health Organization. World health report. Geneva: World Health Organization; 2000.

2. Carrozzi L., Rijcken B., Burney P. et al. Family history for chronic lung diseases and epidemiological determinants of COPD in the three European countries. Eur. Respir. Rev. 2001; 11 (80): 49-54. 
3. Lundbäck B., Viegi G., Jönsson E. et al. Bronchitis symptoms in Italy and Sweden - prevalence and risk factors. Eur. Respir. Rev. 2001; 11 (80): 55-64.

4. Nationale Heart, Lung, and Blood Institute. Morbidity \& mortality: charbook on cardiovascular, lung, and blood diseases. Bethesda, MD: US Department of Health and Human Services, Public Health Service, National Institutes of Health; 1998. Available from: URL: www. Nhlbi.nih.gov/nhlbi/seiin/other/cht-book/thm.

5. British Thoracic Society. BTS guidelines for the management of chronic obstructive pulmonary desease. The COPD Guidelines Group of the Standards of Care Committee of BTS. Thorax 1997; 52 (suppl. 5): S1-S28.

6. Agusti A.G.N., Noguera A., Sauleda J. et al. Systemic effects of chronic obstructive pulmonary desease. Eur. Respir. J. 2003; 21: 347-360.

7. Curtis J.R., Patrick D.L. The assessment of health status among patients with COPD. Eur. Respir. J. 2003; 21 (suppl. 41): 36s-45s.

8. Pauwells R.A., Buist S., Calverley P.M.A. Global strategy for diagnosis, management, and prevention of chronic obstructive pulmonary desease. Am. J. Respir. Crit. Care Med. 2001; 163: 1256-1276.

9. Ware J.E. SF-36 Health Survey. Manual and interpretation guide. Second printing. Boston, Massachusetts: The Health Institute. New England Medical Center; 1997.

10. Jones P.W., Quirk F.H., Baveystock C.M. The St.George's respiratory questionnaire. Respir. Med. 1991; 85 (suppl. B): 25-31.
11. Anthonisen N.R., Connett J.E., Kiley J.P. et al. Effects of smoking intervention and the use of an inhaled anticholinergic bronchodilatator on the rate of decline of FEV1. The Lung Health Study. J.A.M.A. 1994; 272: 14971505.

12. Seemungal T.A., Donaldson G.C., Bhowmik A. et al. Time course and recovery of exacerbations in patients with chronic obstructive pulmonary disease. Am. J. Respir. Crit. Care Med. 2000; 161: 1608-1613.

13. Rice K.L., Rubins J.B., Lebahn F. et al. Withdrawal of chronic systemic corticosteroids in patients with COPD: a randomised trial. Am. J. Respir. Crit. Care Med. 2000; 162: $174-178$.

14. Чучалина А.Г. (ред.) Качество жизни у больных бронхиальной астмой и хронической обструктивной болезнью легких. М.: Атмосфера; 2004.

15. Vestbo J., Sorensen T., Lange P. et al. Long-term effect of inhaled budesonide in mild and moderate chronic obstructive pulmonary disease: a randomised controlled trial. Lancet 1999; 353: 1819-1823.

16. Burge P.S., Calverley P.M., Jones P.W. et al. Randomised, double blind, placebo controlled study of fluticasone propionate in patients with moderate to severe chronic obstructive pulmonary disease: the ISOLDE trial. Br. Med. J. 2000; 320: 1297-1303.

Поступила 26.01.05 (с) Коллектив авторов, 2005 удК 616.24-036.12-07 